\section{A CASE OF CONGENITAL DILATATION OF THE PULMONARY ARTERY}

\author{
BY
}

H. L. HEIMANN, M.D., M.R.C.P.

Lieut.-Col., S.A.M.C.

AND

M. M. POSEL, M.D., M.R.C.P.

Major, S.A.M.C.

(From Oribi Military Hospital, Pietermartizburg, Natal)

(With Photogravure Plate)

According to Bedford, Paff, and Parkinson (1941) congenital dilatation of the pulmonary artery is a rarity, while septal defect is the commonest congenital malformation of the heart. Those authors stress the great dilatation of the pulmonary artery and its branches that accompanies atrial septal defect, and, while attempting to differentiate between these two conditions, confess that differential diagnosis may be impossible. Other authors, notably Assmann (1928), describe this congenital dilatation as a primary condition due to asymmetrical divisions of the truncus arteriosus communis.

Jennes (1936) points out that dilatation of the pulmonary artery is as rare as dilatation of the aorta is common. In a total of 38,000 necropsies done at various English-speaking hospitals no case was discovered up to 1936 . In all, 122 cases have been recognized, and, with the exception of 12 , all at necropsy. From the descriptions of some of these cases they were probably of the type described by Bedford, Paff, and Parkinson. Master (1939) states that in atrial septal defect large auricles result, with enormous $P$ waves. The opinion expressed by Bedford, Paff, and Parkinson (1941) is contrary to this statement: except in a certain proportion of cases, the right auricle was grossly enlarged, but not the left.

Assmann's classification of congenital dilatation of the pulmonary artery appears to be of value, and is as follows:

A. Acquired :

(1) Aneurysm of the pulmonary artery

(2) Perforation of aneurysm of aorta into pulmonary artery

(3) Pulmonary insufficiency from endocarditis

(4) Stasis in pulmonary circulation, as in mitral stenosis

B. Congenital :

(1) Solitary single anomaly (asymmetrical division of truncus arteriosus communis)

(2) Open ductus botalli

(3) Pulmonary stenosis (very exceptional)

(4) Defect of auricular septum

(5) Defect of ventricular septum

Radiology plays an important part in the diagnosis of this condition, and the criteria of $x$-ray diagnosis seem to be as follows :

(1) Increase of pulmonary bow

(2) Small aortic knuckle

(3) Broadening of hilar shadows

(4) Enlargement of the pulmonary arterial tree. The oblique positions, together with the barium swallow, will show the characteristic picture of the enlarged pulmonary artery.

In view of the rarity of the condition, we are adding a description of a case which conforms, radiologically and otherwise, to those already described.

\section{Clinical History}

The patient, a man aged 23, was admitted to hospital because of "feverishness" and pains in the joints. Inflnenza was diagnosed, but routine examination revealed certain peculiar features. He was $6 \mathrm{ft} .5 \frac{1}{2}$ in. in height, and had clubbed fingers and a very blue tinge on his lips. At the age of 10 he had been told that he had " something wrong" with his heart, but this had not precluded him from having a fairly normal adolescence. He had played games at school, but could not run fast. He had had no illnesses and had lost no schooling. Three years previously he had coughed up a cupful of blood, but his doctor told him it was due to "lung strain." He had had no chest pains, cough, or expectoration. Neither had he had any sore throats, joint pains, or any kind of body rash.
The family history was not relevant, except that his father was a very tall man of $6 \mathrm{ft}$. 5 in., and his sister was also over $6 \mathrm{ft}$. The head and neck showed no abnormality. The apex beat was well out, five inches from the mid-sternal line. There was a palpable thrill, diastolic in time, over the praecordium-not like the presystolic thrill of mitral stenosis, but sharp and abrupt. On auscultation there was a mid-diastolic murmur, heard at the apex and conducted out. There were no moist sounds in the lungs. The pulmonary and aortic areas were clear. The liver was not palpable. The blood pressure was $140 / 70$. The Wassermann reaction was negative, and the blood count showed 7,500,000 red cells, $\mathrm{Hb}$ over $140 \%$ (Sahli), and a white cell count of 13,000.

The electrocardiogram did not show a right axis deviation by measurement on the Einthoven triangle. There were inverted $\mathbf{T}$ waves of the coronary type, with depression of the $S-T$ segment below the isoelectric line, in both arm and leg apex leads taken in the conventional manner. The three limb leads showed diaphasic QRS complexes suggestive of congenital heart disease as described by Katz.

$X$-ray examination demonstrated a huge pulmonary artery with a comma-shaped branch, also greatly enlarged in the antero-posterior position (Plate, Fig. 1). After a barium swallow a very large impression made by the right pulmonary artery in the right oblique position was a striking feature (Fig. 2).

We conclude that the above is a case of congenital dilatation of the pulmonary artery and its branches. Atrial septal defect might be present, but this is uncertain, as the right auricle is not grossly enlarged.

BiBLIOGRAPHY

Assmann, H. (1928). Die klinische Röntgendiagnostik der inneren Erkrankungen, Leiprig.

Bedford, D. E., Paff, C., and Parkinson, J. (1941). Brit. Heart J., 3, 36. Jennes, S. W. (1936). Johns Hopk. Hosp. Bull., 59, 133.

Master, A. M. (1939). The Electrocardiographic and X-ray Configuration of the Smith, Lester, et al. (1936). Radiology, 17, 141.

\section{Medical Memoranda}

\section{A Case of Traumatic Ventricular Pneumocephalus}

(With Photogravure Plate)

Cases of traumatic ventricular pneumocephalus reported in this country are few in number, and Davies (1943), who described one case of his own, could find only about twelve in the British literature. It may therefore be of value to put on record another instance of this rare condition.

\section{History OF CASE}

A man aged 33 was found lying alongside a road late at nigit, and was admitted to the Staffordshire General Infirmary on May, 23 . 1943 , in a deeply comatose condition. The exact nature of the accident could not be ascertained, but from the time factors con cerned it was judged that he had been lying out in the cold for at least one hour On examination a small puncture wound, a quarter of an inch in diameter, was found over the left eye, with fairly large abrasions of the forehead and just below the outer canthus of the left eye. The eyelids on both sides were very swollen and could be opened only with difficulty, but enough to show subconjunctival haemorrhage in the left eye. There was no bleeding from the ears or nose, nor was any other injury found. His temperature was subnormal, but the pulse was fairly strong. with a rate of 78 a minute. Fracture of the skull was diagnosed; the patient was admitted and treated for shock. Because of his general condition, surgical toilet was not performed.

By the following morning he had passed into a state of cerebral irritation, and this irritation alternated with long periods of sleep. Dehydration treatment was begun, using a $50 \%$ solution of magnesium sulphate, $4 \mathrm{oz}$. six-hourly, per rectum. By the next day he was completely conscious, and complained of pain in the occipital region. This pain later shifted to the left temporal area, and during his stay in hospital he had repeated attacks of pain in this region.

On the fourth day after admission the patient complained of stiffness of his neck. Examination showed physical signs of meningitis, although temperature and pulse were normal. On lumbar puncture the cerebrospinal fluid was found to be of normal pressure and fairly heavily blood-stained. This fluid contained no coagulum, and the supernatant fluid was faintly yellow. Numerous red blood cells were present, but there was no increase of leucocytes, and films showed only Gram-positive bacilli, while, on culture, only aerial contaminants were found. The dehydration treatment was stopped and the patient put on a course of sulphapyridine, and the meningitic symptoms passed off in a few days.

Apart from the continued headaches, for which phenobarbitone was given, the patient made good progress until June 2, when he 
developed a left-sided supranuclear facial paralysis. The following day the patient was radiographed for the first time, when a massive comminuted fracture extending nearly round the calvarium was found. There was no involvement of the base of the skull, but the $x$-ray film showed perfect outlines of the third and lateral ventricles due to the air in them (see Figs. 1 and 2 on Plate). Another radiograph was taken on June 19; this showed that the air had been absorbed.

About June 25 the patient developed diplopia of the left eye with ectropion of the lower eyelid. The ectropion was due to scarring of an abrasion below the lid; and scarring inside the orbit affecting the external rectus would account for the diplopia, since no injury to the sixth cranial nerve could be found.

The patient made good progress and was discharged after seven weeks in hospital. When seen on July 21 he was complaining of complete deafness in the left ear. The facial paralysis was beginning to pass off, and cutaneous sensation was present on the left side of the face. A radiograph taken in Towne's position showed a fracture extending into the petrous portion of the temporal bone, which would account for the seventh and eighth cranial nerves being affected. The probable route of entry of the air was through either the frontal wound or the ear and then by a dural tear into the subarachnoid space. The air would then rise in the ventricular system to the third and lateral ventricles.

My thanks are due to Mr. G. I. Wilson for his encouragement and advice, and for permission to publish this case.

M. GAINES, L.R.C.P.\&S.Ed., House-surgeon, Staffordshire General Infirmary.

REFERENCE

Davies, D. O. (1943). Brit. J. Surg., 30, 237.

\section{Generalized Sensitivity to Sulphonamides}

The recent article by Major Park (Journal, July 17, p. 69) has drawn attention to a condition of increasing incidence which is at present by no means always recognized. I am therefore prompted to quote the following case of cutaneous hypersensitivity to sulphanilamide powder applied to an extremely minute lesion. This was to the site of a small penile wart which had been cauterized.

\section{CASe History}

The patient was a soldier, aged 23 , of $3 \frac{1}{2}$ years' service; previous occupation, plumber. He had been in hospital for 4 to 5 days a year ago with a rash the details of which I have been unable to obtain. He had never previously taken any sulphonamides.

In March, 1943, he had two small penile warts removed by cauterization, and sulphanilamide powder was applied. He attended a week later, and, as the warts had not disappeared, the process of cautery and powder was repeated, as it was also on the occasion of his next visit, a week after this. He powdered the wart sites three times daily at his unit during this period. The two areas in question were only about 2 to $3 \mathrm{~mm}$. square. At his next attendance, a week later, the warts had gone but the small sites were still unhealed. More powder was given, as was done under similar circumstances at the end of the fou th week. After applying sulphanilamide powder thus for one month to this almost insignificant lesion, his penis swelled up, and he developed a rash on that organ, extensor sutface of arms, and face. This was not seen personally, as he was treited at his unit. The rash subsided in a few days with calamine iution to face and arms and vaseline to the penis. The wart site lotion to face and arms and vaseline to the penis. The wart site
healed, and he went on leave to arrange for his forthcoming marriage.

Two weeks later the wart, however, recurred and he attended hospital again on May 8. He saw a different medical officer, and volunteered no information concerning his skin trouble. The wart was tieated as before with cautery and sulphanilamide powder, and he was detained in hospital to settle finally with it. On May 10 there was some oedema of the prepuce with commencing eczematization. The condition was recognized and saline washes were given. On May 11 he also had dermatitis 'on face, both forearms, and hands, with an erythematous eruption on chest and legs. This settled well by May 18, and his contumacious wart was once more treated -this time by liq. epispasticus and starch and boric powder-and he was discharged from hospital on May 25. He was seen again on June 2, and on June 9 was detained for a patch test. This test was done on lint moistened in axillary sweat, pieces of which, powdered with sulphapyridine, sulphathiazole, sulphadiazine, sulphamethazine, sulphanyl-mandelate, and sulphanilamide respectively, were strapped to the unbroken skin on the back for 24 hours. No action occurred from any of these.

I was tempted to carry out scratch tests and to give him tablets by mouth to see the reaction, but as at long last he was in a fit state to be married after some trying weeks of frustration, he was discharged.

\section{CONCLUSIONS}

Obviously sulphanilamide powder should not be applied to even insignificant lesions for such a lengthy period as above. The fact that a lesion is not healed under sulphanilamide powder within a week should be evidence that it does not suit and that a local or a generalized dermatitis is likely.

\section{R. R. WILlcox, M.B.,}

A/Major, R.A.M.C. ; Specialist in Venereology.

\section{Reviews}

\section{CHAOS IN THE MEDICAL SERVICES}

The Future of Medicine. By D. Stark Murray, B.Sc., M.B., Ch.B. (Pp.

126. 9d.) West Drayton: Penguin Books Ltd.

This addition to the "Penguin Specials" can be cordially recommended. It is packed with interesting information clearly presented. Some of the chapters-e.g., 6 and 7, "Could Medicine Do More?" and "The Chaos which is Medicine To-day"I found particularly stimulating. The patchwork nature of the medical services of this country has long been a byword among those who have studied it, and Dr. Stark Murray manages to deal not only concisely but vividly with a subject which might have been thought threadbare. The ingenious diagram on page 76 , showing " how a family gets its medical service to-day," may be regarded by the reader as either a comedy (of errors!) or a tragedy-depending on one's mood. But though I approve Dr. Murray's diagnosis, I cannot agree with his suggested treatment. While we are all in favour of making it as easy as possible for everybody to get the medical services he requires, it is evident that there is room for honest difference of opinion as to how this is to be done. Dr. Murray is an out-and-out supporter of a whole-time salaried service. For this there is a good case if one is content to adopt the somewhat inhuman attitude of the convinced Socialist, who seems to ignore the individual in his concern for the "community." This is well illustrated by the author's approval of a scornful reference to the "wastefulness" of the visits of several doctors to patients in the same street. This may be called "wasteful" if we ignore the legitimate desires of the average man and woman, but some of us have not yet attained this attitude of superiority to human weakness. I would advise Dr. Murray to try on some of his Socialist friends, ordinary common people, say in Lancashire or Yorkshire, his dislike of this form of "wastefulness"; or perhaps he might vary it by suggesting that it is "wasteful" for a woman to prefer to spread her purchases over various shops, according to her fancies, instead of buying everything at one store. I must confess to a strong dislike for the prospect of a world in which everything, including human nature, is to be planned and managed and levelled out.

There are a few points of detail to which attention may be called. The only factual error I have detected is on page 63, where the author says "there is no longer any restriction of any kind on the sale of patent and proprietary remedies." This overlooks the Pharmacy and Medicines Act of 1941, which puts many restrictions on their sale, and insists, for example, on the publication of their formulae. It was rather surprising to find on page 42 that Dr. Murray says that the patient in a public hospital is " more likely to be treated as a human being than in a voluntary hospital." I should very much doubt this. In his chapter on " The Specialist," which I can heartily commend, Dr. Murray says that it is difficult to define a "consultant." Surely a real " consultant" is one whose opinion is valued by his peers. On page 78 the author says that the "panel patient's wife in a very large proportion of cases calls in her own private doctor, a quite different person." This does not agree with what I have been told by many general practitioners.

I hope this little book will have a wide circulation; that its diagnosis of the chaotic position of the medical services of this country will be pondered by many who have not thought about it; but that its prescription for the cure of the disease may be very carefully measured by a reference to what the reader would desire for himself. Men and women have little use for the "community" when they are sick, and the main use of medical services for most of us must continue for a long time to be when we are sick. Whatever changes we make - and Dr. Murray convincingly shows that many are overduewe must not mechanize and dehumanize the relations between patient and doctor.

Alfred Cox. 
H. I. HEIMANN AND M. M. POSEL: CONGENITAL DILATATION OF PULMoNARY ARTERY

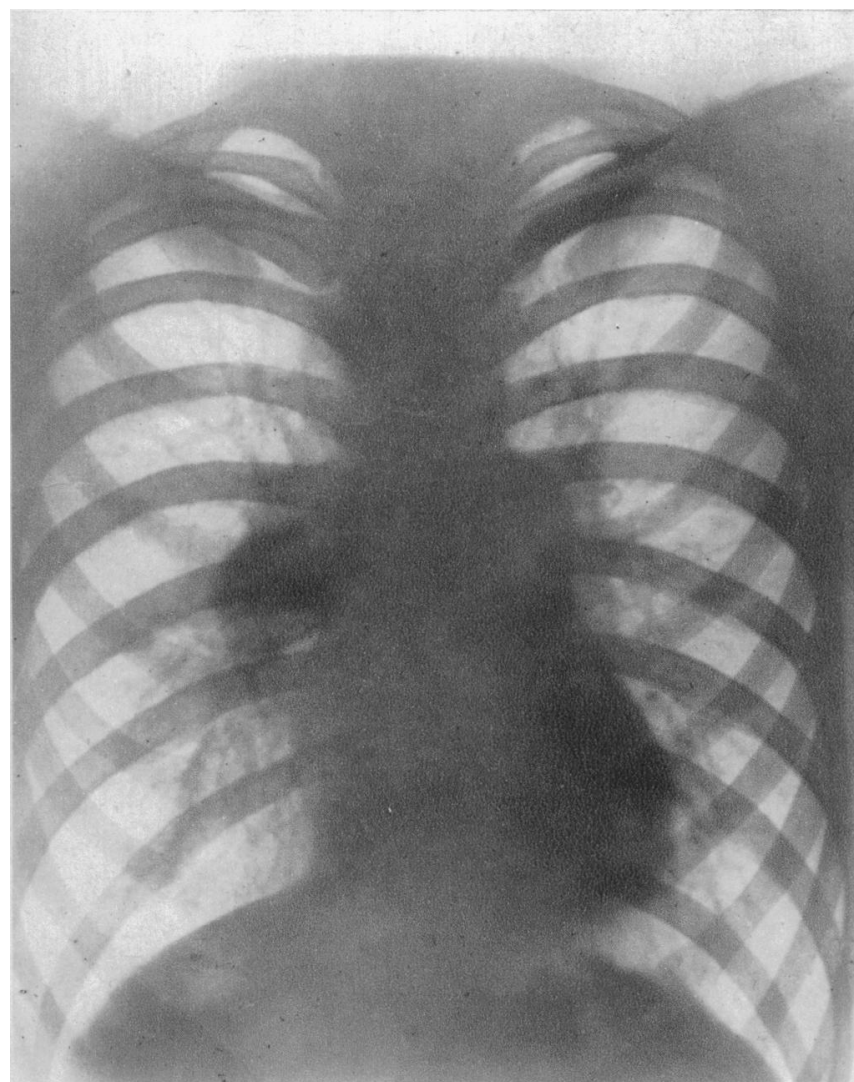

Fig. 1.-Large pulmonary artery with comma-shaped branch.

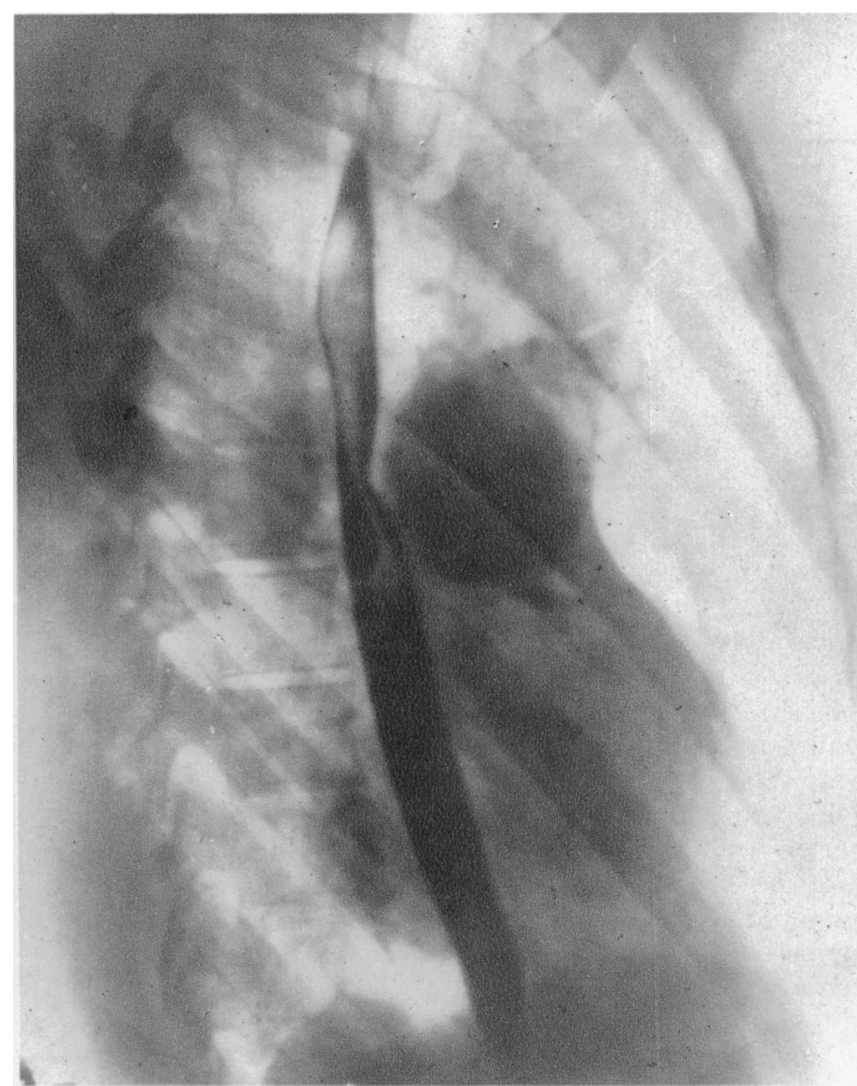

Fia. 2.-Oblicque view after harium swallow, showing impression on oesophagus by right pulmonary artery.

M. GAINES : TRAUMATIC VENTRICULAR PNEUMOCEPHALUS

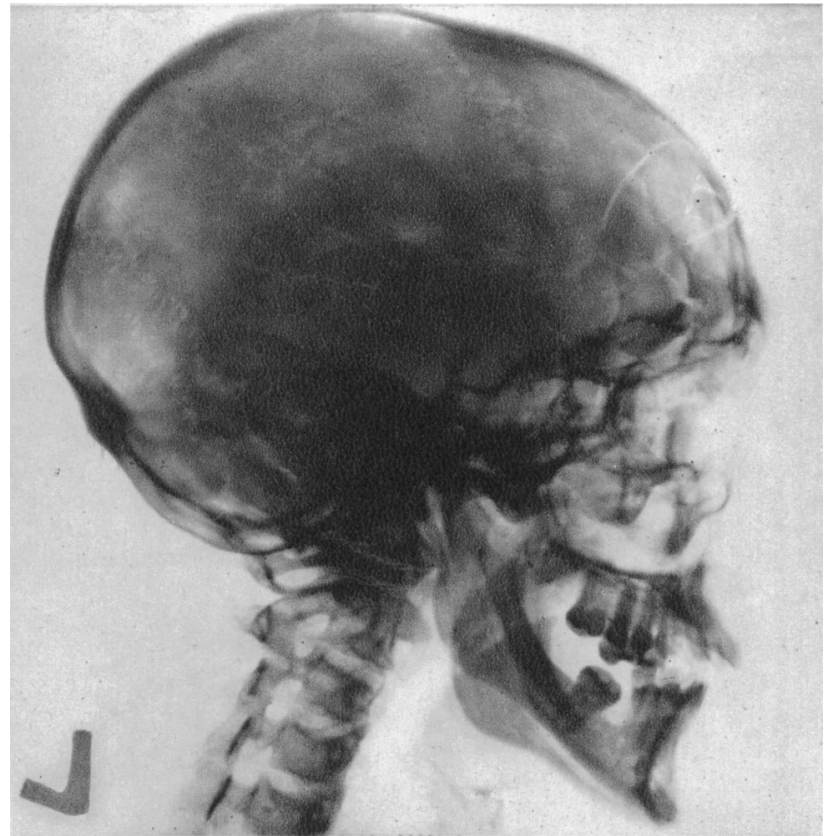

FIG. 1.-Lateral radiograph of skull, June 3, 1943.

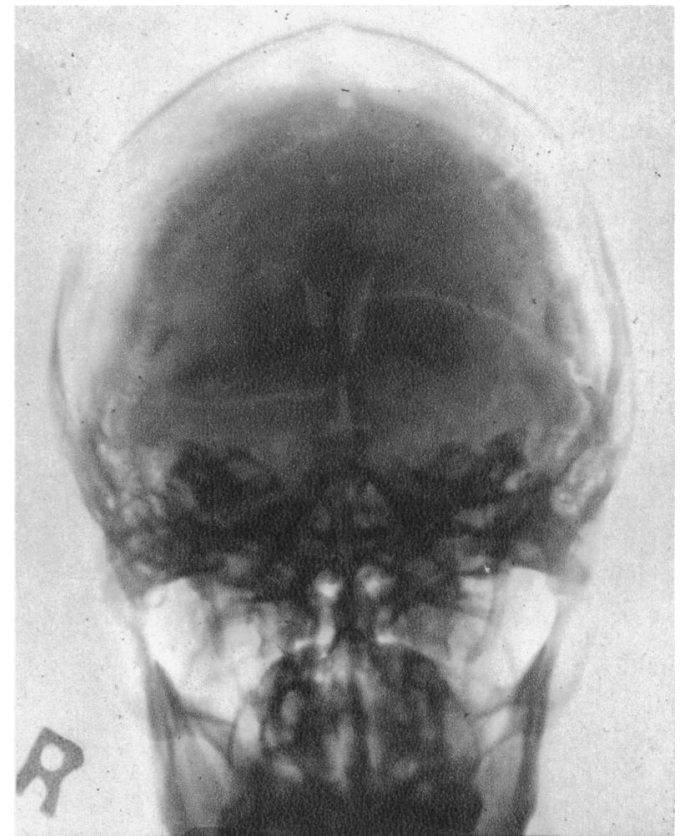

Fig. 2.-Antero-posterior radiograph, June 3, 1943. 